\title{
Uncovering high-level corruption: Cross- national objective corruption risk indicators using public procurement data
}

Mihály Fazekas (University of Cambrige), Gábor Kocsis (Government Transparency Institute)

Accepted for publication in British Journal of Political Science

Acceptance date: 11/5/2017

\section{Abstract}

Measuring high-level corruption is subject to extensive scholarly and policy interest with moderate progress in the last decade. We develop two objective proxy measures of high-level corruption in public procurement: single bidding in competitive markets and a composite score of tendering 'red flags'. Using official government data of 2.8 million contracts in 28 European countries in 2009-2014, it directly operationalizes a common definition of corruption: unjustified restriction of access to public contracts to favour a certain bidder. Corruption indicators are calculated at the contract level, but produce aggregate indices consistent with well-established country-level indicators, and also validated by micro-level tests. The utility of the novel indicators is demonstrated through modelling the effect of red tape on corruption. Data is published at www.digiwhist.eu. 


\section{INTRODUCTION}

Measuring corruption received extensive academic and policy attention due to the central role it plays in the quality of democracy, the provision of public goods, and economic growth. Some international organisations monitor corruption in their member countries or tie funding to corruption ratings. Recognising the lack of reliable and actionable corruption indicators, repeated calls have been made to develop so-called second generation governance indicators better suited to aiding policy making and hypothesis testing. However only limited progress has been made. ${ }^{1}$

In order to address the lack of actionable corruption indices, we develop novel proxy measures of grand corruption which: 1) match a specific corruption definition; 2) derive from objective data; 3) allow for consistent temporal and cross-country comparisons on large samples; and 4) can be validated using alternative corruption proxies.

We develop the measurement of grand corruption in public procurement as it constitutes roughly $30 \%$ of government spending in OECD countries, it is a data-rich area, and perceived as a corrupt sector. Our domain-specific definition of corruption is: "The aim of corruption [in public procurement] is to steer the contract to the favoured bidder without detection. This is done in a number of ways, including avoiding competition through, e.g., unjustified sole sourcing or direct contracting awards; or favouring a certain bidder by

\footnotetext{
${ }^{1}$ Knack, Kugler, and Manning 2003; Sequeira 2012.
} 
tailoring specifications, sharing inside information, etc." ${ }^{2}$ This definition focuses attention on restricted and unfair access to public resources, i.e. particularism. ${ }^{3}$

\section{LITERATURE ON MEASURING CORRUPTION}

Available indicators are often inadequate for testing theories of grand corruption and developing effective solutions to it. Most corruption indicators derive from surveys of attitudes, perceptions and experiences of corruption among different stakeholders (e.g. general population, firms, experts); reviews of institutional features supposed to control corruption; and audits and investigations of individual cases.

Among perception and attitude surveys, the two most widely used are the World Bank's Control of Corruption ${ }^{4}$ and Transparency International's Corruption Perceptions Index 5 . Both of these have received extensive criticism applicable to any similar survey ${ }^{6}$. Critics point out that perceptions may or may not be related to actual experience ${ }^{7}$. They can be driven by general sentiment reflecting, for example, prior economic growth ${ }^{8}$ or recent media coverage of high profile corruption cases $^{9}$. Perceptions of grand

\footnotetext{
${ }^{2}$ World Bank 2009, 7.

${ }^{3}$ Mungiu-Pippidi 2006; North, Wallis, and Weingast 2009; Rothstein and Teorell 2008.

${ }^{4}$ Kaufmann et al 2010.

5 Transparency International 2012.

${ }^{6}$ Andersson and Heywood 2009; Lambsdorff 2006.

${ }^{7}$ Rose and Peiffer 2015.

${ }^{8}$ Kurtz and Schrank 2007.

${ }^{9}$ Golden and Picci 2005.
} 
corruption are even more unreliable than perceptions of everyday corruption since experts and citizens have almost no direct experience of it. These indicators are typically produced from non-representative surveys, therefore representativeness bias is likely to occur (i.e. capturing the views of a particular group rather than the whole population), in addition to reflexivity bias (i.e. respondents influenced by prior and future measurements) exaggerated by small samples ${ }^{10}$. Furthermore, many such indices vary surprisingly little over time in spite of apparent large changes in the underlying governance structures suggesting that they are insensitive to change ${ }^{11}$. Surveys of experiences with low-level bribery, such as the Quality of Government Institute's regional survey, ${ }^{12}$ address some weaknesses of perception surveys, while still suffering from others such as non- or false response to sensitive questions about bribing. Most importantly, only a tiny fraction of the population has direct experience with grand corruption limiting the use of this method.

Reviews of institutions controlling corruption, ${ }^{13}$ while crucial in understanding the determinants of corruption, are, by design, not measuring corruption directly. Without a precisely measured outcome variable, they have to rely on untested theories of which institutional features work. Scientific analyses and audits of individual cases are highly reliable in establishing both petty and grand corruption, however, their narrow scope and lack of

\footnotetext{
10 Golden and Picci 2005.

${ }^{11}$ Arndt and Oman 2006.

${ }^{12}$ Charron et al 2014.

13 Transparency International 2012.
} 
representativeness make them of limited use for comparative purposes. In addition, data from courts and law enforcement agencies typically cannot be compiled to create corruption indices because courts have little capacity to investigate large number of cases and there is a high risk of capture in corrupt countries. An innovative exception to this general observation is Escresa and Picci (2016) who exploit the independence of US courts from foreign corrupt groups in enforcing the Foreign Corrupt Practices Act.

Some authors, recognising the need for further indicators, have developed objective corruption proxies which rely on directly observable behaviours that likely indicate corrupt behaviour (for an overview see: Fazekas, Tóth, \& King, 2016). These studies investigate corruption in various contexts such as elections and high-level politics or welfare services and redistributive programs. Many of these innovative indicators are context-dependent and are prohibitively expensive to replicate over time and across countries.

More closely associated with our approach are those studies which focus on corruption in public procurement. For example, Golden and Picci (2005) propose a new measure of corruption based on the difference between the quantity of infrastructure and the related public spending among 20 regions in Italy. Our proxies are inspired by authors using red-flags in public procurement as proxy measures for corruption such as the use of exceptional procedure types ${ }^{14}$ or single bidding ${ }^{15}$.

\footnotetext{
${ }^{14}$ Auriol et al 2016.

${ }^{15}$ Klasnja 2016.
} 


\section{DATA}

The data derives from public procurement announcements in 2009-2014 in the EU27 (excluding Malta) and Norway. Announcements appear in the Tenders Electronic Daily (TED), which is the online version of the 'Supplement to the Official Journal of the EU', dedicated to European public procurement ${ }^{16}(\mathrm{DG}$ GROWTH, 2015). The data represents a complete database of all public procurement procedures conducted under the EU Public Procurement Directives in the EU27 plus Norway regardless of the funding source (e.g. national, EU funded). All government contracts above given value thresholds ${ }^{17}$ have to follow transparency and procedural rules of the Directives with a few exceptions (e.g. some defence contracts). All countries' public procurement legislation is within the framework of the Directives, national datasets are therefore directly comparable ${ }^{18}$. The regulation of government contracting in WTO member states and a global Open Contracting Data Standard suggest that similar datasets can be constructed globally ${ }^{19}$.

Data is entered by the procuring organisations into standard reporting forms following a common EU reporting guide. The received data is checked by the

\footnotetext{
${ }^{16}$ DG GROWTH 2015.

17 E.g. services contracts above 209000 EUR in 2016 have to be published in TED. See thresholds: https://simap.ted.europa.eu/european-public-procurement.

${ }^{18}$ European Commission 2014.

19 See reviews: http://digiwhist.eu/publications/towards-a-comprehensive-mapping-of-
} information-on-public-procurement-tendering-and-its-actors-across-europe/; 
EU's Publications Office. In spite of this, there is a non-negligible amount of missing or nonsensical data. The database used is from the European Commission - DG GROWTH ${ }^{20}$ which conducted further data quality checks and enhancements. TED contains variables appearing in 1) calls for tenders such as product specification, application deadline, or assessment criteria, and 2) contract award notices such as name of the winner, awarded contract value, or date of contract signature. For every observed tender, we have information from contract award announcements as publication is always mandatory, while information from calls for tenders may not be published under specific circumstances.

The TED database contains over 2.8 million contracts of which 2.3 million are used in the analysis due to the following exclusions: 1) countries with too few observations (Malta), 2) contracts below mandatory reporting thresholds, and 3) contracts on non-competitive markets. Database and corruption proxies are downloadable: http://digiwhist.eu/resources/data/.

\section{MEASUREMENT MODEL}

This section outlines the measurement logic while full technical details including regression specifications are in Annex $A$.

The measurement model approximates our corruption definition according to which corruption works when legally prescribed principles of open and fair competition are circumvented by public officials when designing and running tenders in order to recurrently award government contracts to connected

20 Download at https://open-data.europa.eu/en/data/dataset/ted-csv 
companies. Thus, it is possible to identify the output and input sides of the corruption process: lack of bidders for government contracts (output) and means of fixing the procedural rules for limiting competition (inputs). Corruption proxies are obtained by measuring the degree of unjustified restriction of competition in public procurement. Such corruption indicators signal risk of corruption rather than actual corruption. They are expected to be correlated with corrupt exchanges rather than perfectly matching them.

Such proxy indicators signal corruption only if competition is expected in the absence of corruption, hence, markets which are non-competitive under noncorrupt circumstances had to be excluded (e.g. markets for specialised services). Small markets (defined by product group and location) with a low number of potential bidders were excluded constituting $8 \%$ of contracts, underlining that their vast majority concern widely supplied products.

The simplest indication of restricted competition reflecting our corruption definition is when only one bid is submitted for a tender on a competitive market (output side) (for further discussion of single bidding see Charron, Dahlström, Fazekas, \& Lapuente, 2017; Fazekas, Tóth, et al., 2016). This typically allows awarding contracts above market prices and extracting corrupt rents. Recurrent single bidder tenders between a buyer and a supplier allow for developing interpersonal trust underpinning corrupt contracting. This is to say that while individual instances of single bidding may be explained by a number of non-corrupt reasons (e.g. known most productive bidder), recurrent or extensively used single bidder contracts in a public organisation or region are more likely to signal corruption and restricted access. Hence, the incidence of single bidder contracts (i.e. 
contracts awarded in procurement tenders where only one bid was submitted) is the most basic corruption proxy proposed.

The more complex indication of corruption also incorporates characteristics of the tendering process that are determined by public officials conducting the tender and contributing to competition restriction (input side). This composite indicator, which we call the Corruption Risk Index (CRI), is a simple arithmetic average of individual risk indicators, falling between 0 and 1 , with 1 representing the highest observed corruption risk and 0 the lowest.

Based on qualitative interviews with public procurement actors, a media review and a review of the academic and policy literature, we identified a long list of potential 'red flags' of corruption and associated corruption techniques. 'Red flags' are differentiated from 'green flags' using statistical techniques to avoid over-reliance on a small number of known examples disregarding the diversity of public procurement markets. Thus, we implemented binary logistic regressions to model the input-output relationships between single bidding and other corruption 'red flags', also containing a wide set of control variables (e.g. buyer sector). Those indicators were identified as valid 'red flags' which were significant and substantive predictors of single bidding. For continuous variables such as advertisement period length (days) we defined 'red flag' categories using cutpoints in order to capture the non-linear character of corruption, while maximizing predictive power.

This process led to the following $\mathrm{CRI}$ components in addition to single bidding (descriptive statistics and exact definitions in Annex B and D): 
1. A simple way to fix tenders is to avoid the publication of the call for tenders in the official public procurement journal as this makes it harder for non-connected competitors to prepare bids. This is only relevant in non-open procedures where publication is voluntary.

2. While open competition is relatively hard to avoid in some procedure types such as open tender, others such as invitation tenders are by default less competitive; hence using less open and transparent procedure types can indicate the deliberate limitation of competition.

3. A too short advertisement period (number of days between publishing a tender and submission deadline), can inhibit nonconnected bidders in preparing adequate bids while the buyer informally informs the favoured bidder about the opportunity ahead of time. Alternatively, the advertisement period becomes lengthy due to legal challenge which may also signal corruption risks.

4. Subjective, hard-to-quantify evaluation criteria (e.g. quality of company organigram) rather than quantitative or price-related criteria allows rigged assessment procedures as it creates room for discretion and limits accountability mechanisms. Alternatively, price-only criteria can also be abused for corruption when the connected firm bids with the lowest price knowing that quality will not be monitored.

5. If the time used to decide on the submitted bids is excessively short or lengthy, it can signal corruption risks. Snap decisions may reflect premediated assessment, while long decision period and the corresponding legal challenge suggests outright violation of laws. 
The strength of the single bidder indicator is that it is very simple and easily interpreted. However, it is also more prone to gaming by corrupt actors such as including fake bidders to mimic competition. For justified purchases of highly specific products or when the most productive supplier is known, single bidding may over-estimate corruption risks, even though defining highly specific purchases to match the specific characteristics of connected bidders is a major form of corrupt contracting.

The strength of the composite indicator approach is a more complete monitoring of the corrupt contracting process, while it also explicitly tries to abstract from diverse market realities to capture underlying corruption techniques. It allows for 'red flag' definitions to change from context to context in order to capture similar levels of risk irrespective of the detailed forms of corruption techniques used (e.g. non-corrupt competitive conditions imply tighter submission deadlines in the Netherlands than in Greece, hence corrupt behaviour would reflect deviations from slightly different normal benchmarks). This flexibility in corruption indices aims to assure that the same level of risk is associated with a similar level of actual corruption in a comparative perspective. As corruption techniques are likely to change over time, tracking multiple corruption strategies in one composite score is most likely to remain consistent. Both of these characteristics underpin its usefulness for international and time-series comparative research. The main weakness of $\mathrm{CRI}$ is that it can only capture a subset of corruption strategies, arguably the simplest ones, hence it misses out on sophisticated types of corruption such as corruption combined with inter-bidder collusion. As long as simplest strategies are the cheapest, they likely represent the most 
widespread forms of corrupt behaviour. However, it is admitted that more sophisticated corruption techniques are more likely to be used when monitoring institutions are stronger, implying that the level of corruption may be under-estimated in less corrupt countries. Further research should expand on the set of red flags tracked and evaluate the interaction between monitoring institutions, regulatory complexity, and corruption sophistication in order to more precisely estimate corruption.

\section{REGRESSION RESULTS}

The above described binary logistic regression model was implemented in 6 specifications to show the independent effect of each 'red flag' on single bidding (models 1-5) and their combined effect (model 6) (Table 1). Descriptive statistics of the dependent variable (single bidding) can be found in Annex C. These highlight the wide variation in single bidding practice across Europe.

The hypothesised relationships between single bidding and corruption techniques are supported by estimation results. In a database encompassing enormous diversity across 28 countries and 6 years in 2.3 million contracts, our simple regression models perform well by explaining $13-15 \%$ of variance in single bidding.

Not publishing the call for tenders in the official journal (TED) increases the average probability of single received bid in every regression by $12-18$ percent, which is one of the strongest impacts across all models. Non-open procedure types carry a higher corruption risk than open procedures in terms 
of the probability of single bid in all our models: they are associated with 1419 percent higher single bid probability. Evaluation criteria behaves as expected with both price-only and the excessive use of non-quantitative criteria carrying corruption risks: risky criteria are associated with 4 percent higher probability of single bidding across the different models compared to the reference category. Extremely short or lengthy advertisement periods are associated with about $1 \%$ higher probability of a single bid received across the different models compared to the normal or typical advertisement periods. Extremely short or long decision periods are estimated to increase the probability of single bidding by $3-6 \%$ compared to typical decision period lengths. While some of these average estimated effects seem small, they only reflect the Europe-wide relationship, in specific countries some 'red flags' impacts are considerably stronger than in others. 
Table 1. Binary logistic regression results on contract level, 2009-2014, EU27+Norway, average marginal effects reported, $\mathrm{N}=1,306,025$, all regressions contain control variables: buyer sector, buyer type, year, product market, contract value, country

\begin{tabular}{|c|c|c|c|c|c|c|}
\hline \multirow{2}{*}{$\begin{array}{l}\text { Dependent variable } \\
\text { Model }\end{array}$} & \multicolumn{6}{|c|}{ single bid=1 } \\
\hline & (1) & $(2)$ & (3) & (4) & (5) & (7) \\
\hline $\begin{array}{l}\text { no call for tender } \\
\text { published }\end{array}$ & $0.182^{* *}$ & & & & & $0.120^{* *}$ \\
\hline & $(0.000)$ & & & & & $(0.000)$ \\
\hline restricted procedure & & $\begin{array}{l}0.188^{\star *} \\
(0.000)\end{array}$ & & & & $\begin{array}{l}0.141^{\star *} \\
(0.000)\end{array}$ \\
\hline risky evaluation criteria & & & $\begin{array}{l}0.038^{* *} \\
(0.000)\end{array}$ & & & $\begin{array}{l}0.039 * * \\
(0.000)\end{array}$ \\
\hline $\begin{array}{l}\text { extreme submission } \\
\text { period }\end{array}$ & & & & $0.008^{* *}$ & & $0.014^{\star *}$ \\
\hline & & & & $(0.000)$ & & $(0.000)$ \\
\hline $\begin{array}{l}\text { extreme decision } \\
\text { period }\end{array}$ & & & & & $0.034^{\star *}$ & $0.057^{\star *}$ \\
\hline & & & & & $(0.000)$ & $(0.000)$ \\
\hline R-squared & 0.143 & 0.145 & 0.135 & 0.135 & 0.136 & 0.151 \\
\hline
\end{tabular}

Note: $p$-values in parentheses, ${ }^{*} \mathrm{p}<0.05,{ }^{* *} \mathrm{p}<0.01$ 
Based on these regression results and theory, we could identify 'red flags' of corruption: single bidding and further components of the CRI. For simplicity, each 'red flag' is weighted equally making CRI a simple arithmetic average of its components. Additivity reflects the interchangeability of different corruption techniques used to achieve corrupt deals and that more 'red flags' mark a contracting process which is more in line with our corruption model, that is making corruption more likely to occur. Nevertheless, it is once again underlined that sophisticated corrupt actors may only need to use only one of the measured corruption techniques to render a procedure corrupt, making the composite score a lower bound estimate of true corruption risks. Component weights are normed so that $\mathrm{CRI}$ falls between 0 and 1 (i.e. weights were set at $1 / 6)$. Such a simple weighting allows easy interpretability of changes in $\mathrm{CRI}$ scores, i.e. changes can be thought of in terms of additional 'red flags'.

\section{VALIDATING THE CORRUPTION PROXIES}

The validity of single bidder and $\mathrm{CRI}$ indicators stems from their correspondence with the definition of high-level corruption in public procurement and the fitted regression models. Analysis of their association with micro-level objective corruption proxies and with widely used surveybased macro-level corruption indicators further underpin their validity, i.e. suggest that they proxy corruption rather than other phenomena such as low administrative capacity. Main results are discussed here, additional validity tables can be found in Annex B. 
First, we test validity through two micro-level objective risk indicators: procurement suppliers' country of origin and contract prices. It is expected that a contract represents a higher corruption risk if it is awarded to a company registered in a tax haven as secrecy allows for hiding corrupt money ${ }^{21}$. As expected, across EU27 plus Norway there is a marked and significant difference in corruption risks of contracts won by foreign companies registered in tax havens versus those which are not: 0.28 versus 0.26 for single bidding; 0.34 versus 0.31 for $\mathrm{CRI}\left(\mathrm{N}_{\text {contract }}=28,642\right)$.

We also expect corruption to drive prices up. Although reliable unit prices are not available across many sectors, we can employ an alternative indicator of price, which is the ratio of actual contract value to initially estimated contract value $^{22}$. As expected, both single bidder contracts and a higher CRI are associated with higher prices. Single bidder contracts have between $9-9.6 \%$ higher prices than multiple bidder contracts. Contracts with one additional red flag (i.e. 1/6 CRI points higher) are 2.5-2.7\% more pricey after controlling for major confounding factors (Table 2). To complement the full population estimations with more reliable, but small sample price information, we manually collected unit price information from procurement announcements for new computed tomography scanners (CT machines) and new highway and road construction. Both tests support validity.

\footnotetext{
21 Shaxson and Christensen 2014.

22 Coviello and Mariniello 2014.
} 
Table 2. Linear regressions explaining relative contract value and unit prices, EU27+NO, 2009-2014

\begin{tabular}{|c|c|c|c|c|c|c|c|c|}
\hline \multirow{2}{*}{$\begin{array}{l}\text { Dependent variables } \\
\text { Model }\end{array}$} & \multicolumn{4}{|c|}{$\begin{array}{l}\text { Relative contract value (contract } \\
\text { price/estimated price) }\end{array}$} & \multicolumn{2}{|c|}{ eur/CT machine } & \multicolumn{2}{|c|}{ eur/km } \\
\hline & $(1)$ & (2) & (3) & (4) & $(5)$ & (6) & $(7)$ & (8) \\
\hline \multirow[t]{2}{*}{ Independent variables } & $\begin{array}{l}\text { Single } \\
\text { bidder }\end{array}$ & $\mathrm{CRI}$ & $\begin{array}{l}\text { Single } \\
\text { bidder }\end{array}$ & $\mathrm{CRI}$ & $\begin{array}{l}\text { Single } \\
\text { bidder }\end{array}$ & $\mathrm{CRI}$ & $\mathrm{CRI}$ & $\mathrm{CRI}$ \\
\hline & $\begin{array}{l}0.0963^{* *} \\
(0.00)\end{array}$ & $\begin{array}{c}0.1484^{* *} \\
(0.00)\end{array}$ & $\begin{array}{c}0.0903^{* *} \\
(0.00)\end{array}$ & $\begin{array}{l}0.1607^{* *} \\
(0.00)\end{array}$ & $\begin{array}{l}557,505^{*} \\
(0.02)\end{array}$ & $\begin{array}{c}881,525^{+} \\
(0.10)\end{array}$ & $\begin{array}{c}7,854,589^{+} \\
(0.06)\end{array}$ & $\begin{array}{l}7,561,906^{+} \\
(0.10)\end{array}$ \\
\hline Buyer sector & $\mathrm{N}$ & $\mathrm{Y}$ & $\mathrm{N}$ & $\mathrm{Y}$ & $\mathrm{N}$ & $\mathrm{N}$ & $\mathrm{N}$ & $\mathrm{N}$ \\
\hline Buyer type & $\mathrm{N}$ & $Y$ & $\mathrm{~N}$ & $Y$ & $\mathrm{Y}$ & $Y$ & $\mathrm{~N}$ & $\mathrm{~N}$ \\
\hline Year & $\mathrm{N}$ & $\mathrm{Y}$ & $\mathrm{N}$ & $\mathrm{Y}$ & $\mathrm{Y}$ & $\mathrm{Y}$ & $\mathrm{Y}$ & $\mathrm{N}$ \\
\hline Product market & $\mathrm{N}$ & $Y$ & $\mathrm{~N}$ & $Y$ & $\mathrm{~N}$ & $\mathrm{~N}$ & $\mathrm{~N}$ & $\mathrm{~N}$ \\
\hline Contract value & $\mathrm{N}$ & $Y$ & $\mathrm{~N}$ & $Y$ & $\mathrm{~N}$ & $\mathrm{~N}$ & $\mathrm{~N}$ & $\mathrm{~N}$ \\
\hline Country & $Y$ & $Y$ & $Y$ & $Y$ & $Y$ & $Y$ & $Y$ & $\mathrm{~N}$ \\
\hline CT machine quality & & & & & $\mathrm{Y}$ & $\mathrm{Y}$ & & \\
\hline Terrain ruggedness & & & & & & & $\mathrm{N}$ & Y \\
\hline $\begin{array}{l}\text { Construction sector price } \\
\text { level }\end{array}$ & & & & & & & $\mathrm{N}$ & $\mathrm{Y}$ \\
\hline $\mathrm{N}$ & 524442 & 501784 & 524441 & 501783 & 68 & 68 & 73 & 62 \\
\hline R-squared & 0.1096 & 0.1546 & 0.0710 & 0.1248 & 0.32 & 0.284 & 0.188 & 0.165 \\
\hline
\end{tabular}


While corruption perceptions are considered to be too sticky and biased to adequately capture changes in corruption, they are more reliable for comparing levels of corruption across countries for a longer time period ${ }^{23}$. Hence, correlating levels of subjective and objective corruption indicators by country can provide a further validity test. The 2009-2013 country average single bidder and CRI indicators correlate as expected with widely used perception-based corruption indicators such as Transparency International's Corruption Perception Index (coefficients are around 0.6). A 2013 Eurobarometer survey of bidding companies' experience of corruption across the EU provides the most directly comparable survey-based indicator of corruption in public procurement (Standard Eurobarometer 79). Higher values indicate higher reported experience of corruption, hence moderate positive linear correlation coefficients (0.56-0.62) also support indicator validity.

\section{CONCLUSIONS}

This article developed two objective proxies of high-level corruption: a simple indicator - single bidding - and a complex indicator - CRI. Both indicators have been validated by their direct fit with our corruption definition, an empirical model of corrupt rent extraction, and a range of external validity test.

The great advantage of our approach is that a large amount of data is already available for research across high, middle and low income countries, starting from about 2008. Such data is being generated on a daily basis by national procurement systems adding to databases automatically on a real-time basis at no additional cost. As the proposed corruption risk indicators are calculated on the transaction level they also allow a move away from country-level analysis to look into regions, sectors,

${ }^{23}$ Escresa and Picci 2016. 
organisations, or individual persons' behaviour long advocated as necessary for advancing the field. Such large volumes of internationally comparative micro-level data open up a new horizon for comparative research on corruption and quality of institutions more broadly. Subsequent research could benefit from using corruption proxies which avoid subjective indicators' biases and the context-bound nature of most objective indices. Using corruption proxies which are sensitive to change allow for better assessing interventions and testing theories of institutional change such as the impact of increasing salaries on corruption or electoral accountability and corruption at the municipal level, to name a few.

The proposed corruption proxies can also be used in policy for understanding what works in anticorruption. They can be used to evaluate single regulatory or organisational changes such as tightening reporting requirements or introducing organisational integrity management. They could also guide regulators in where to spend their limited resources for conducting audits. In addition, corruption proxies can be made available to citizens, NGOs and journalists to hold governments accountable.

In order to increase the reliability and validity of corruption risk measurement, further research could identify and measure additional corruption risk techniques as more data becomes available; and it could also use more advanced analytics to differentiate justified instances of competition restriction such as product specificity from unjustified, favouritistic cases. 


\section{BIBLIOGRAPHY}

Charron, N., Dahlström, C., Fazekas, M., \& Lapuente, V. (2017). Careers, Connections, and Corruption Risks: Investigating the impact of bureaucratic meritocracy on public procurement processes. Journal of Politics, 79(1), 89103.

Chong, E., Klien, M., \& Saussier, S. (2015). The Quality of Governance and the Use of Negotiated Procurement Procedures: Evidence from the European Union (EPPP DP No. 2015-3). Paris.

DG GROWTH. (2015). TED Structured Dataset (2009-2014), Tenders Electronic Daily, supplement to the Official Journal of the European Union. Brussels.

Escresa, L., \& Picci, L. (2016). Trends in Corruptions Around the World. European Journal on Criminal Policy and Research, 22(3), 543-564.

Fazekas, M., Cingolani, L., \& Tóth, B. (2016). A comprehensive review of objective corruption proxies in public procurement: risky actors, transactions, and vehicles of rent extraction (Government Transparency Institute Working Paper Series No. GTI-WP/2016:03). Budapest.

Fazekas, M., Tóth, I. J., \& King, L. P. (2016). An Objective Corruption Risk Index Using Public Procurement Data. European Journal of Criminal Policy and Research, 22(3), 369-397.

Golden, M. A., \& Picci, L. (2005). Proposal for a New Measure of Corruption, illustrated with Italian data. Economics \& Politics, 17(1), 37-75.

Klasnja, M. (2016). Corruption and the Incumbency Disadvantage: Theory and Evidence. Journal of Politics, 77(4), 928-942.

OECD. (2007). Integrity in Public Procurement. Good Practice from A to Z. Paris: OECD.

Pricewaterhouse Coopers. (2013). Identifying and reducing corruption in public procurement in the EU. Brussels: PricewaterhouseCoopers and Ecorys.

Sequeira, S. (2012). Advances in Measuring Corruption in the Field. In D. Serra \& L. Wantchekon (Eds.), New Advances in Experimental Research on Corruption (pp. 145-176). Bingley, UK: Emerald Publishing.

Transparency International. (2006). Handbook for Curbing Corruption in Public Procurement. Berlin: Transparency International.

World Bank. (2009). Fraud and Corruption. Awareness Handbook. Washington DC: World Bank. 


\section{ANNEXES}

\section{ANNEX A - FULL DESCRIPTION OF THE MEASUREMENT MODEL}

Our approach builds on prior work with similar datasets making use of a range of public procurement 'red flags' 24 . The measurement model directly approximates our corruption definition according to which corruption works when legally prescribed principles of open and fair competition are circumvented by public officials during the implementation of procurement rules in order to recurrently award government contracts to companies belonging to the particularistic network. By implication, it is possible to identify the output and input sides of the corruption process: lack of bidders for government contracts (output) and means of fixing the procedural rules for limiting competition (inputs). ${ }^{25}$ By measuring the degree of unjustified restriction of competition in public procurement, proxy indicators of corruption can be obtained. ${ }^{26}$ The identified corruption indicators, however, only signal risk of corruption rather than actual corruption. They are expected to be correlated with corrupt exchanges rather than perfectly matching them.

Such proxy indicators signal corruption risks only if competition is to be expected in the absence of corruption on the markets in question. This implies that markets

24 (Charron et al., 2017; Fazekas, Cingolani, et al., 2016; Klasnja, 2016).

25 These inputs of the corrupt tendering process represent process design choices of public buyers as their decisions are indispensable for corruption to occur. Of course, companies must be complicit too, even though they cannot by law design procurement tenders.

${ }^{26}$ Corruption can also be achieved in the post award phase which necessitates contract modification (e.g. increasing contract value) which is a more costly form of corruption as there are stringent rules on contract renegotiations all across Europe. This is to say that some forms of corruption are naturally not captured by our indicators, still the expectation is that the biggest part is captured. 
which are non-competitive under non-corrupt circumstances have to be excluded such as markets for specialised services. In order to identify markets which are noncompetitive by nature, we relied on market size as measured by number of contracts awarded. Markets with less than 10 contracts awarded in $2009-2014^{27}$ were considered as likely not able to sustain multiple competing firms even under noncorrupt circumstances. Markets were defined by a matrix of product groups (CPV ${ }^{28}$ categories at level 3) and geographical location of contract performance (NUTS ${ }^{29}$ regions at level 2). This condition excluded $8 \%$ of all awarded contracts, underlining that the vast majority of government purchases concern widely supplied goods and services.

The simplest indication of restricted competition in line with our theoretical definition is when only one bid is submitted ${ }^{30}$ in a tender on an otherwise competitive market.

27 In the absence of company identifiers in the EU-wide public procurement dataset to actually calculate the number of different competing firms, we derived the contract number cut-off point by analysing the United Kingdom subsample where we manually assigned company IDs by matching names and addresses to official registry records. Cross tabulating number of contracts awarded on the market and the number of different companies supplying the UK government shows that the number of markets with less than 2 companies drops below 5\% among markets with at least 11 contracts awarded, with the average number of companies steadily increasing as the number of contracts increase. Hence taking 10 contracts per market is a conservative cut-point for identifying competitive markets with multiple potential suppliers.

${ }^{28} \mathrm{CPV}=$ Common Procurement Vocabulary. For more info see: http://simap.europa.eu/codes-and$\underline{\text { nomenclatures/codes-cpv/codes-cpv en.htm }}$

29 NUTS=Nomenclature of territorial units for statistics. For more info see: http://epp.eurostat.ec.europa.eu/portal/page/portal/nuts nomenclature/introduction

30 According to correspondence with DG GROWTH officials, TED may contain the number of valid bids, that is after inadequate bids are rejected, rather than the number of submitted bids in some 
This typically allows the awarding of contracts above market prices and extracting corrupt rents (output side). In addition, recurrent single bidder tenders between a buyer and a supplier allow for developing interpersonal trust underpinning corrupt contracting. This is to say that while individual instances of single bidding may be explained by a number of non-corrupt reasons, recurrent or extensively used single bidder contracts in a public organisation or region are more likely to signal corruption and restricted access. Hence, the incidence of single bidder contracts awarded (i.e. contracts awarded in procurement tenders where only one bid was received by the contracting authority) is the most basic corruption proxy we propose.

The more complex indication of high-level corruption also incorporates characteristics of the tendering process that are in the hands of public officials who conduct the tender and contribute to competition restriction (input side). This composite indicator, which we call the Corruption Risk Index (CRI), is defined as follows:

$$
\begin{aligned}
& C R I^{i}=\Sigma_{j} w_{j}{ }^{*} \mathrm{Cl}_{j}{ }^{i} \\
& \Sigma_{j} w_{j}=1 \\
& 0 \leq C R I^{i} \leq 1 \\
& 0 \leq C l_{j}^{j} \leq 1
\end{aligned}
$$

cases as the official guidance documents are not clear enough. Using the number of submitted bids rather than valid bids leads to an underestimation of corruption risks as excluding all but one bid on administrative grounds such as a missing stamp from one of the certificates, represents a corruption technique on its own (Fazekas, Tóth, et al., 2016). 
where $\mathrm{CRl}^{i}$ stands for the corruption risk index of contract $i, \mathrm{Cl}_{\mathrm{j}}{ }^{i}$ represents the $j$ th elementary corruption indicator observed in the tender of contract $i$, and $\mathbf{w}_{\mathbf{j}}$ represents the weight of elementary corruption indicator $j$. Elementary corruption indicators or 'red flags' can be either corruption inputs or outputs. $\mathrm{CRI}=0$ indicates minimum corruption risk while $\mathrm{CRI}=1$ denotes maximum corruption risk observed.

Based on qualitative interviews with participants of public procurement tenders, a media review and a review of the academic and policy literature, we identified a long list of potential 'red flags' of corruption and the associated corruption techniques. Qualitative interviews were carried out with public procurement practitioners 'close' to corrupt transactions to identify widely used corruption techniques, to explore the underlying rationale for each of them, and to gather specific examples (without concrete names). We conducted 54 semi-structured interviews each lasting for about 1-1.5 hours in 5 countries: Germany, Italy, Hungary, Sweden, and the UK. Interviewees covered all three major actor categories in public procurement (issuers, bidders, and advisors). They work in construction, healthcare, and IT services sectors taking part in projects ranging from large infrastructure projects of millions of EUR to small services contracts of few thousand EUR.

The media review entailed content analysis of articles appearing in 9 major online newspapers in Hungary between 2008 and 2015. Relevant articles were identified by standard keyword search in the online portals' archives using a range of words relating to corruption and public procurement. The so-identified sample then was manually checked to select those cases which contain concrete enough information to identify corruption techniques or 'red flags'. Eventually, 47 relevant articles were used for detailed corruption technique mapping. 
The review of the literature encompassed widely cited academic papers reviewing corruption measurement and research papers using public procurement corruption proxies similar to ours; while we also reviewed the policy literature on corruption prevention, corruption identification and in general good practice guides ${ }^{31}$ (Chong, Klien, \& Saussier, 2015; Klasnja, 2016; OECD, 2007; Pricewaterhouse Coopers, 2013; Sequeira, 2012; Transparency International, 2006; World Bank, 2009).

Full list of corruption red flags identified based on these diverse sources can be found in (Fazekas, Cingolani, \& Tóth, 2016). These indicators range from tender announcement through contract award to contract implementation. Many of which cannot currently be reliably calculated on the EU-wide TED dataset, while further data collection work will be able to generate the detailed data needed for some additional indicators.

'Red flags' had to be reliably differentiated from 'green flags'32 using statistical techniques to avoid the usual trap of 'red flag' approaches which are driven by a small number of known examples disregarding the diversity of public procurement markets. We implemented binary logistic regression models in order to directly model the input-output relationships between corruption 'red flags' and statistically differentiate between reliable 'red flags' and 'green flags'. Binary logistic regression

31 Chong, Klien, and Saussier 2015; Klasnja 2016; OECD 2007; Pricewaterhouse Coopers 2013; Sequeira 2012; Transparency International 2006; World Bank 2009.

${ }^{32}$ Green flags are considered those characteristics or combination of characteristics of the tendering process which are widely associated with good practices of open and fair competition such as leaving a sufficiently long time period for bidders to prepare their bids or defining tender specifications in producer neutral, generic terms which allow for technologically different but functionally equivalent products to compete. 
is preferable over standard techniques used for measuring latent variables such as PCA or SEM because, it allows for isolating the effect of interchangeable corruption techniques rather than assuming they are all correlated, it also provides an efficient framework for dealing with non-linearities, moreover it also allows for using control variables which are not meant to be 'red flags' still influence single bidding probability. Regression analysis is predominantly meant to capture systematic associations between inputs and outputs of the corrupt contracting process reflecting the corrupt groups' control, while they may also reflect some causal relationships.

The following model was estimated:

$$
\begin{aligned}
& \operatorname{Pr}\left(\text { single } \text { bidder }_{\mathrm{i}}=1\right)=\frac{1}{1+\mathrm{e}^{-Z_{i}}} \\
& Z_{i}=\beta_{0}+\beta_{1 j} R_{i j}+\beta_{4 m} C_{i m}+\varepsilon_{i}
\end{aligned}
$$

where single bidder ${ }_{i}$ equals 1 if the th contract awarded had only one bidder and 0 if it has more; $Z_{i}$ represents the logit of a contract being a single bidder contract; $\beta_{0}$ is the constant of the regression; $R_{i j}$ is the matrix of $j$ corruption 'red flags' for the ith contract such as length of advertisement period; $C_{i m}$ stands for the matrix of $m$ control variables for the th contract such as the number of competitors on the market; $\varepsilon_{i}$ is the error term; and $\beta_{1 j}$, and $\beta_{4 m}$ represent the vectors of coefficients for explanatory and control variables.

Each regression includes the full list of control variables except for one (model 6 in Table 2). Control variables account for the most important alternative explanations to our conceptualised corrupt outcome such as low administrative capacity and product market idiosyncrasies, in particular: (1) institutional endowments measured by type (e.g. municipal, national) and sector (e.g. education, healthcare) of contracting body, 
(2) differences in technology and market standards proxied by type of product procured using 40 different CPV divisions (e.g. financial services, construction works), (3) differences due to contract size and complexity indicated by contract value (logarithm, EUR), and (4) institutional framework as proxied by country and year of contract award. Once again, we run our regressions only on competitive markets. Descriptive statistics for these variables can be found in Annex C.

A logically equivalent, but practically different approach was used for identifying 'red flags' in categorical and continuous variables using the above regression model in each of the 28 countries analysed. For categorical variables, those categories were denoted as 'red flags' which turned out to be significant and substantial predictors of single bidding compared to the available most transparent and competitive category (e.g. open procedure in the case of procedure types contracting bodies can use when procuring). 'Red flags' in continuous variables were identified in an iterative process: first, a model was fitted using the linear continuous predictor; second, two discrete jumps in residual values were identified using residual distribution graphs. These discrete jumps or thresholds represent the points beyond which the probability of single bidding drastically changes. We looked for two thresholds for each continuous variable because both extremes of the distributions could represent high risk such as in the case of decision periods where snap decisions as well as unusually lengthy decisions could signal corruption albeit for slightly different reasons. While the exact threshold values may contain a certain degree of professional judgement, the fact that they enter into the regression models as significant and substantial predictors provides substantial evidence for their validity. In order to preserve the full population of observations, we always included a missing category in every corruption input. In some cases, missing values predicted single 
bidding suggesting that concealing relevant tender information from bidders or the wider public served as a corruption technique, hence deserved to be included as 'red flag'. Risky categories and thresholds also differ by country reflecting the diverse market norms for contracting entities and bidding firms (e.g. high risk short advertisement period in Greece was up to 44 days, while only up to 27 days in the UK). Such diversity of 'red flag' definitions is supposed to capture the underlying corruption technique within each context by abstracting from different environmental conditions and norms. ${ }^{33}$ The full definition of country-specific 'red flags' can be found in Appendix D.

After testing each red flag available in the EU-wide dataset and validated by prior research ${ }^{34}$, we derived the following comparatively valid reliably computable components of $\mathrm{CRI}$ in addition to single bidding (overview in Table 1, descriptive statistics and exact definitions in Annex B and D):

1. A simple way to fix tenders is to avoid the publication of the call for tenders in the official public procurement journal (Tenders Electronic Daily (TED)) as this would make it harder for non-connected competitors to get informed about the opportunity and hence to prepare their bids. This is only relevant in non-open procedures where publication is up for decision as in open procedures publication is mandatory.

2. While open competition is relatively hard to avoid in some tendering procedure types such as open tender, others such as invitation tenders or

\footnotetext{
${ }^{33}$ As predicting the incidence of single bidding defined 'red flags', higher as well as lower frequency of risky categories per country resulted avoiding the problem of selecting only the outliers in the distributions more or less representing the same proportion of contracts in each country.

${ }^{34}$ (Charron et al., 2017).
} 
direct contracting are by default less competitive because they allow for picking directly who can submit bids. By implication, using less open and transparent procedure types can indicate the deliberate limitation of competition and favouring a connected bidder, that is corruption risks.

3. If the advertisement period, i.e. the number of days between publishing a tender and the submission deadline, is too short for preparing an adequate bid, it can serve corrupt purposes whereby the contracting body informally tells the favoured company about the opportunity ahead of time allowing it to properly prepare its bid. Alternatively, when the advertisement period becomes lengthy, it may also signal corruption risks because often legal challenge against the call for tenders specification or the chosen procedure type lies behind (e.g. an excluded company challenging the exclusion criteria set out in the call for tenders, as was the case in the European Commission vs Hungarian Government case regarding criteria used in highway construction tenders $\left.{ }^{35}\right)$.

4. Different types of evaluation criteria are prone to manipulation to different degrees, subjective, hard-to-quantify criteria such as the quality of company organigram rather than quantitative or price-related criteria often accompany rigged assessment procedures as it creates room for discretion and limits accountability mechanisms. In some cases, nevertheless, price-only criteria can also be abused for corrupt goals whereby the well-connected firm bids with the lowest price knowing that quality will not be monitored thoroughly or a contract modification will allow for charging higher prices. 
5. If the time used to decide on the submitted bids is excessively short or lengthy, it can signal corruption risks. Snap decisions may reflect premediated assessment, that is when there was no serious consideration of bids because the winner was already known. A long decision period is often due to a legal challenge mounted against the decision making process or the initial award decision whereby the announcement of the final, binding award decision is delayed until the first instance court or arbitration board reached a conclusion. In such cases the suggested outright violation of laws is the foundation for defining corruption risks.

Table A1. Overview of corruption 'red flags'

\begin{tabular}{|c|c|c|}
\hline Proc. phase & Indicator name & Indicator values \\
\hline \multirow{3}{*}{ Submission } & $\begin{array}{l}\text { Call for tenders } \\
\text { publication (non- } \\
\text { open procedures) }\end{array}$ & $\begin{array}{l}0=\text { call for tender published in official } \\
\text { journal } \\
1=\mathrm{NO} \text { call for tender published in } \\
\text { official journal } \\
0=\text { open }\end{array}$ \\
\hline & Procedure type & $\begin{array}{l}1=\text { non-open (accelerated, restricted, } \\
\text { award without publication, negotiated, } \\
\text { tender without competition) }\end{array}$ \\
\hline & $\begin{array}{l}\text { Length of } \\
\text { advertisement } \\
\text { period }\end{array}$ & $\begin{array}{l}\text { Number of days between the } \\
\text { publication of call for tenders and the } \\
\text { submission deadline }\end{array}$ \\
\hline Assessment & Evaluation criteria & $\begin{array}{l}\text { Sum of weights for evaluation criteria } \\
\text { which are NOT related to prices and } \\
\text { quantitative requirements }{ }^{36}\end{array}$ \\
\hline
\end{tabular}

${ }^{36}$ In TED, information on award criteria was available in an unstructured text variable along with the weight of each criterion. Applying text mining techniques, looking for keywords such as price, cost, wage, etc., we calculated the weight of quantitative criteria standardized between 0 and 100, 0 meaning no quantitative criteria was considered in the awarding process, 100 implying that there was only quantitative criteria considered. In those countries, when there were too few contracts with qualitative information on weights (i.e. texts for text mining), we used a binary variable available in every contract award announcement which takes value 0 if "Most economically advantageous tender" and 1 if "Lowest price" criteria was used. 


\begin{tabular}{lll} 
& $\begin{array}{l}\text { Length of decision } \\
\text { period }\end{array}$ & $\begin{array}{l}\text { Number of days between submission } \\
\text { deadline and announcing contract } \\
\text { award }\end{array}$ \\
\hline \multirow{3}{*}{ Outcome } & $\begin{array}{l}\text { Single bidder } \\
\text { contract } \\
\text { (valid/received) }\end{array}$ & $\begin{array}{l}0=\text { more than } 1 \text { bid received } \\
1=1 \text { bid received }\end{array}$ \\
\hline
\end{tabular}

Each of the two corruption risk indicators, single bidding and $\mathrm{CRI}$, have its pros and cons. The strength of the single bidder indicator is that it is very simple and straightforward to interpret. However, it is also more prone to gaming by corrupt actors due to its simplicity such as including fake bidders to mimic competition. In the case of justified purchases of highly specific products, single bidding may overestimate corruption risks, even though defining highly specific purchases to match the specific characteristics of the connected bidder is reportedly a major form of corrupt contracting.

The strength of the composite indicator approach $(\mathrm{CRI})$ is that it explicitly tries to abstract from diverse market realities to capture the underlying corruption techniques. It allows for 'red flag' definitions to change from context to context in order to capture similar levels of risk irrespective of the detailed forms of corruption techniques used (e.g. normal competitive conditions imply tighter submission deadlines in the Netherlands than in Greece, hence corrupt behaviour would reflect deviations from slightly different normal benchmarks). This flexibility in corruption indices aims to assure that the same level of risk is associated with a similar level of actual corruption in a comparative perspective. In addition, as corruption techniques used at any point in time are likely to be diverse, tracking multiple possible corruption strategies in one composite score is most likely to remain consistent even if the composition of underlying corruption techniques changes. Both of these characteristics underpin its usefulness for international and time-series comparative 
research. The main weakness of $\mathrm{CRI}$ is that it can only capture a subset of corruption strategies, arguably the simplest ones, hence it misses out on sophisticated types of corruption such as corruption combined with inter-bidder collusion. As long as simplest strategies are the cheapest for corrupt groups, they are likely to represent the most widespread forms of corrupt behaviour. However, it is admitted that more sophisticated corruption techniques are more likely to be used when monitoring institutions are stronger, implying that the level of corruption may be under-estimated in less corrupt countries. Further research should expand on the set of red flags tracked and evaluate the interaction between monitoring institutions, regulatory complexity, and corruption sophistication in order to more precisely estimate corruption. 


\section{ANNEX B - ADDITIONAL VALIDITY TESTS}

Table B1: Bivariate Pearson correlations of \% single bidder and the CRI with survey-based corruption indicators, on the country level, 2009-2013

\begin{tabular}{|c|c|c|c|}
\hline Indicator & $\begin{array}{l}\text { Single } \\
\text { bidder }\end{array}$ & $\mathrm{CRI}$ & $\mathrm{N}$ \\
\hline WGI - Control of Corruption (2013) & $-0.7120^{*}$ & $-0.6933^{*}$ & 28 \\
\hline TI- Corruption Perceptions Index (2013) & $-0.6903^{*}$ & $-0.6662^{*}$ & 28 \\
\hline $\begin{array}{l}\mathrm{GCl} \text { - Favouritism in decisions of government } \\
\text { officials (2013) }\end{array}$ & $-0.7003^{*}$ & $-0.6342^{*}$ & 28 \\
\hline $\begin{array}{l}\text { Eurobarometer company corruption } \\
\text { perceptions (2013) }\end{array}$ & $0.5645^{\star}$ & $0.6163^{*}$ & 25 \\
\hline
\end{tabular}


Table B2: Correlation between individual components of CRI and corruption perceptions, 2009-2013, EU27 pus Norway

\begin{tabular}{|lllllll|}
\hline & $\begin{array}{l}\text { Single } \\
\text { bidder }\end{array}$ & No CFT & $\begin{array}{l}\text { Procedure } \\
\text { type }\end{array}$ & $\begin{array}{l}\text { Weight of } \\
\text { non-price crit. }\end{array}$ & $\begin{array}{l}\text { Adv. } \\
\text { period }\end{array}$ & $\begin{array}{l}\text { Dec. } \\
\text { period }\end{array}$ \\
\hline $\begin{array}{l}\text { WGI - Control of Corruption (2013) } \\
\text { TI - Corruption Perceptions Index } \\
\text { (2013) }\end{array}$ & -0.7120 & -0.1350 & -0.0954 & -0.3634 & -0.1715 & -0.1206 \\
$\begin{array}{l}\text { GCl - Favouritism in decisions of } \\
\text { government officials (2013) }\end{array}$ & -0.6903 & -0.1323 & -0.0832 & -0.3525 & -0.1731 & -0.1118 \\
N & -0.7003 & -0.1223 & -0.0444 & -0.3962 & -0.0209 & -0.1359 \\
\hline $\begin{array}{l}\text { Eurobarometer company } \\
\text { corruption perceptions (2013) }\end{array}$ & 28 & 28 & 25 & 27 & 25 & 28 \\
N & 0.5645 & -0.0658 & -0.1308 & 0.4002 & 0.1406 & 0.1819 \\
\hline
\end{tabular}




\section{ANNEX C - DESCRIPTIVE STATISTICS OF CORRUPTION 'RED FLAGS'}

Table C1. Descriptive statistics of corruption inputs, 2009-2014, EU27 plus Norway

\begin{tabular}{|lccccc|}
\hline & mean & $\min$ & $\max$ & sd & $\mathrm{N}$ \\
\hline Single bidder contract & 0.232 & 0.00 & 1.00 & 0.42 & 1892421 \\
Call for tender not published in official & 0.387 & 0.00 & 2.00 & 0.64 & 2381467 \\
journal & & & & & \\
Length of submission period in days & 44.358 & 1.00 & 784 & 20.48 & 1661258 \\
Relative price of tender & 0.849 & 0.3 & 1 & 0.17 & 542613 \\
documentation & 47 & 0.00 & 100 & 31.39 & 992329 \\
Weight of non-price evaluation criteria & 87.06 & 1 & 31851 & 101.89 & 1544507 \\
\hline Length of decision period in days & & & & &
\end{tabular}

Figure C1. Average \% single bidding contracts by country, 2009-2014, EU27 plus Norway

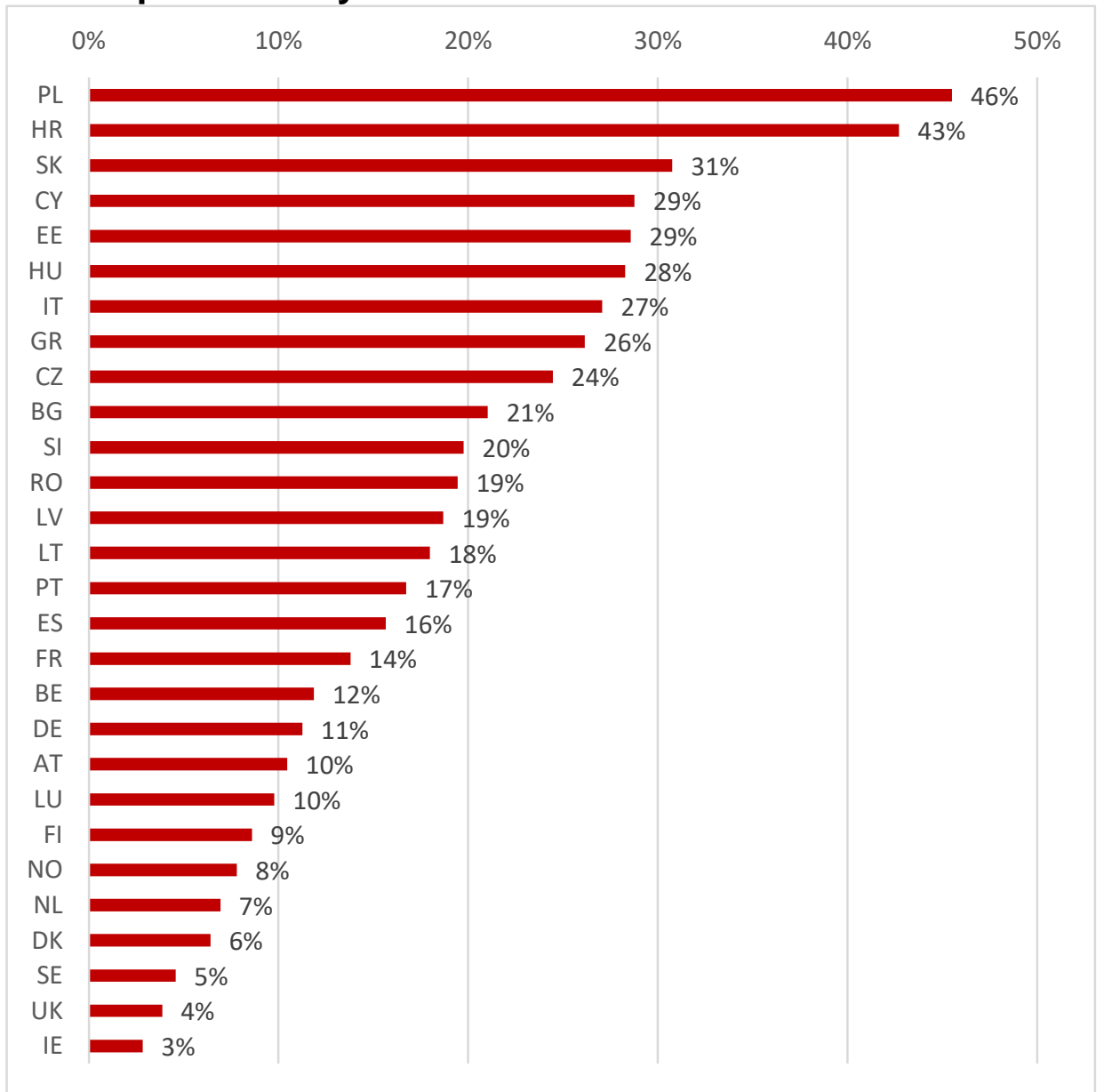


Figure C2. Average \% single bidding contracts by product group (CPV divisions), 2009-2014, EU27 plus Norway

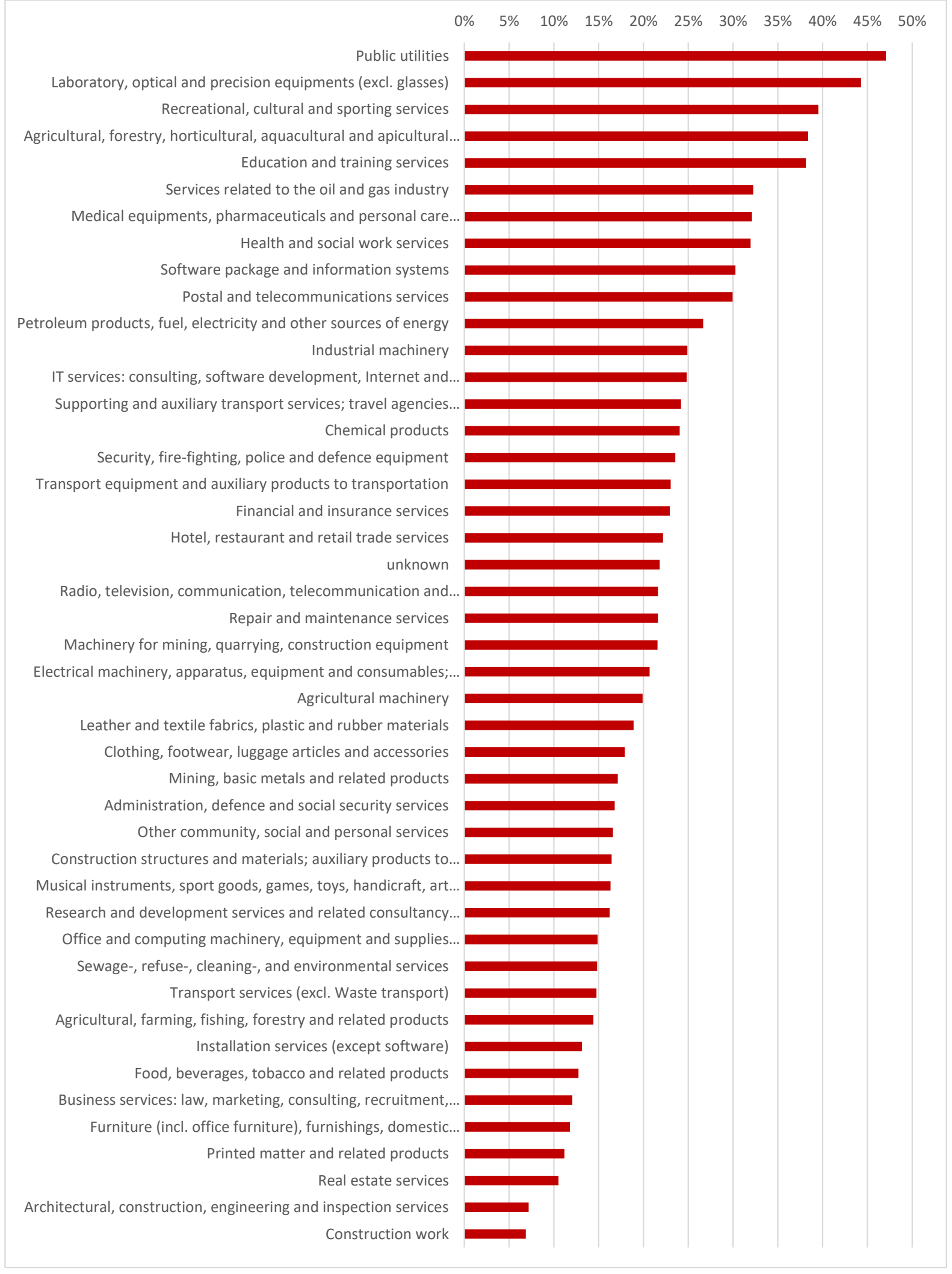


Table C2. Distribution of procedure type, 2009-2014, EU27 plus Norway

\begin{tabular}{|lrr|}
\hline Type of procedure type followed & $\mathrm{N}$ & $\%$ \\
\hline Accelerated negotiated procedure & 4,253 & 0.18 \\
Accelerated restricted procedure & 12,780 & 0.54 \\
Award without publication & 60,198 & 2.53 \\
Competitive dialogue & 3,664 & 0.15 \\
Negotiated with competition & 107,701 & 4.52 \\
Negotiated without competition & 51,942 & 2.18 \\
Open & $1,997,843$ & 83.89 \\
Restricted & 127,336 & 5.35 \\
Missing/error & 15,750 & 0.66 \\
\hline Total & $2,381,467$ & 100 \\
\hline
\end{tabular}


ANNEX D - DESCRIPTIVE STATISTICS OF CONTROL VARIABLES

Table D1. Descriptive statistics of log contract value, 2009-2014, EU27 plus Norway

\begin{tabular}{|lccccc|}
\hline Variable name & mean & $\min$ & $\max$ & $\mathrm{sd}$ & $\mathrm{N}$ \\
\hline log real contract value & 10.866 & 5.14 & 23.03 & 2.43 & $1,678,656$ \\
\hline
\end{tabular}

Table D2. Distribution of issuer type, 2009-2014, EU27 plus Norway

\begin{tabular}{|lcc|}
\hline Type of issuer & $\mathrm{N}$ & $\%$ \\
\hline Central government & 190,387 & 7.99 \\
Local authorities & 558,596 & 23.46 \\
Water, energy, transport, and & 145,029 & 8.09 \\
telecom & 8,416 & 0.35 \\
EU institutions & 695,618 & 29.21 \\
Body governed by public law & 43,708 & 1.84 \\
National or federal Agency/Office & 52,859 & 2.22 \\
Regional or local Agency/Office & 550,01 & 23.10 \\
Other & 136,844 & 5.57 \\
\hline Missing & $2,381,467$ & 100 \\
\hline Total & & \\
\hline
\end{tabular}


Table D3. Distribution of issuer main sector, 2009-2014, EU27 plus Norway

\begin{tabular}{lrr|}
\hline Main sector of issuer & \multicolumn{1}{c}{$\mathrm{N}$} & \multicolumn{1}{c}{$\%$} \\
\hline Defence & 46,082 & 1.94 \\
Economical & 30,860 & 1.30 \\
Education & 120,841 & 5.07 \\
Electricity & 37,303 & 1.57 \\
Environment & 39,830 & 1.67 \\
General public services & 420,814 & 17.67 \\
Health & 779,992 & 32.75 \\
Housing & 68,893 & 2.89 \\
Missing & 197,444 & 8.29 \\
Other & 256,511 & 10.77 \\
Port/airport-related & 7,500 & 0.31 \\
Postal & 15,286 & 0.64 \\
Production & 7,563 & 0.32 \\
Public order & 28,274 & 1.19 \\
Railway & 35,841 & 1.50 \\
Recreation & 12,494 & 0.52 \\
Social & 19,189 & 0.81 \\
Water & 9,968 & 0.42 \\
Missing & 246,782 & 10.36 \\
\hline Total & $2,381,467$ & 100 \\
\hline
\end{tabular}

Table D4. Distribution of contract award year, 2009-2014, EU27 plus Norway

\begin{tabular}{|lrr|}
\hline Year of contract award & $\mathrm{N}$ & $\%$ \\
\hline 2009 & 339,386 & 14.25 \\
2010 & 376,224 & 15.80 \\
2011 & 401,016 & 16.84 \\
2012 & 417,897 & 17.55 \\
2013 & 418,965 & 17.59 \\
2014 & 427,979 & 17.97 \\
\hline Total & $2,381,467$ & 100.00 \\
\hline
\end{tabular}


Table D5. Distribution of main market of contract, 2009-2014, EU27 plus Norway

\begin{tabular}{|c|c|c|}
\hline Main market of contract & $\mathrm{N}$ & $\%$ \\
\hline Agricultural, farming, fishing, forestry and related products & 8,952 & 0.38 \\
\hline Petroleum products, fuel, electricity and other sources of energy & 44,654 & 1.88 \\
\hline Mining, basic metals and related products & 4,857 & 0.20 \\
\hline Food, beverages, tobacco and related products & 98,641 & 4.15 \\
\hline Agricultural machinery & 2,730 & 0.11 \\
\hline Clothing, footwear, luggage articles and accessories & 15,869 & 0.67 \\
\hline Leather and textile fabrics, plastic and rubber materials & 4,010 & 0.17 \\
\hline Printed matter and related products & 16,424 & 0.69 \\
\hline Chemical products & 17,875 & 0.75 \\
\hline $\begin{array}{l}\text { Office and computing machinery, equipment and supplies except furniture and } \\
\text { software packages }\end{array}$ & 46,499 & 1.96 \\
\hline Electrical machinery, apparatus, equipment and consumables; Lighting & 18,878 & 0.79 \\
\hline Radio, television, communication, telecommunication and related equipment & 12,356 & 0.52 \\
\hline Medical equipment, pharmaceuticals and personal care products & 771,803 & 32.45 \\
\hline Transport equipment and auxiliary products to transportation & 74,890 & 3.15 \\
\hline Security, fire-fighting, police and defence equipment & 8,708 & 0.37 \\
\hline $\begin{array}{l}\text { Musical instruments, sport goods, games, toys, handicraft, art materials and } \\
\text { accessories }\end{array}$ & 4,085 & 0.17 \\
\hline Laboratory, optical and precision equipments (excl. glasses) & 33,632 & 1.41 \\
\hline $\begin{array}{l}\text { Furniture (incl. office furniture), furnishings, domestic appliances (excl. lighting) } \\
\text { and cleaning products }\end{array}$ & 47,527 & 2.00 \\
\hline Collected and purified water & 434 & 0.02 \\
\hline Industrial mach & 15,370 & 0.65 \\
\hline Machinery for mining, quarrying, construction equipment & 6,128 & 0.26 \\
\hline $\begin{array}{l}\text { Construction structures and materials; auxiliary products to construction } \\
\text { (excepts electric apparatus) }\end{array}$ & 34,711 & 1.46 \\
\hline Construction work & 270,515 & 11.37 \\
\hline Software package and information systems & 11,723 & 0.49 \\
\hline tenance services & 69,893 & 2.94 \\
\hline software) & 1,299 & 0.05 \\
\hline nt and retail trade services & 14,732 & 0.62 \\
\hline rvices (excl. Waste transport) & 95,938 & 4.03 \\
\hline nd auxiliary transport services; travel agencies services & 4,676 & 0.20 \\
\hline and telecommunications services & 18,736 & 0.79 \\
\hline Public u & 5,165 & 0.22 \\
\hline d insurance services & 59,150 & 2.49 \\
\hline ervices & 3,372 & 0.14 \\
\hline onstruction, engineering and inspection services & 95,656 & 4.02 \\
\hline onsulting, softw & 41,439 & 1.74 \\
\hline id related consultancy services & 7,968 & 0.34 \\
\hline urity services & 5,271 & 0.22 \\
\hline ed to the oil & 888 & 0.04 \\
\hline Itural and apicultural services & 62,789 & 2.64 \\
\hline vices: law, marketing, consulting, recruitment, printing and security & 81,213 & 3.41 \\
\hline d training services & 57,102 & 2.40 \\
\hline ial work ser & 56,833 & 2.39 \\
\hline and environmental services & 107,701 & 4.53 \\
\hline Recr & 7,243 & 0.30 \\
\hline Other community, social and personal services & 10,114 & 0.43 \\
\hline Total & $2,378,449$ & 100 \\
\hline
\end{tabular}


Table D6. Distribution of contracts by country, 2009-2014, EU27 plus Norway

\begin{tabular}{|l|rr|}
\hline Country & \multicolumn{1}{|c|}{$\mathrm{N}$} & Percent \\
\hline AT & 15,082 & 0.63 \\
BE & 31,429 & 1.32 \\
BG & 33,423 & 1.40 \\
CY & 4,872 & 0.20 \\
CZ & 28,036 & 1.18 \\
DE & 157,993 & 6.63 \\
DK & 25,676 & 1.08 \\
EE & 7,308 & 0.31 \\
ES & 111,705 & 4.69 \\
FI & 34,034 & 1.43 \\
FR & 725,636 & 30.47 \\
GR & 16,709 & 0.70 \\
HR & 4,058 & 0.17 \\
HU & 28,177 & 1.18 \\
IE & 14,183 & 0.60 \\
IT & 102,286 & 4.30 \\
LT & 32,905 & 1.38 \\
LU & 3,543 & 0.15 \\
LV & 56,148 & 2.36 \\
NL & 28,772 & 1.21 \\
NO & 16,786 & 0.70 \\
PL & 547,373 & 22.98 \\
PT & 10,386 & 0.44 \\
RO & 86,917 & 3.65 \\
SE & 43,152 & 1.81 \\
SI & 33,721 & 1.42 \\
SK & 12,965 & 0.54 \\
UK & 168,192 & 7.06 \\
\hline Total & $2,381,467$ & 100.00 \\
\hline & &
\end{tabular}


ANNEX E - RED FLAG DEFINITIONS

Table E1. Lack of call for tenders publication in TED red flags by country, 2009-2014, EU27 plus Norway

\begin{tabular}{|l|c|}
\hline $\begin{array}{l}\text { Country } \\
\text { code }\end{array}$ & $\begin{array}{c}\text { NO Call for Tenders } \\
\text { publication is red flag }\end{array}$ \\
\hline AT & Yes \\
BE & Yes \\
BG & No \\
CY & Yes \\
CZ & Yes \\
DE & Yes \\
DK & No \\
EE & No \\
ES & No \\
FI & Yes \\
FR & Yes \\
GR & Yes \\
HR & Yes \\
HU & Yes \\
IE & Yes \\
IT & Yes \\
LT & No \\
LU & Yes \\
LV & Yes \\
NL & Yes \\
NO & Yes \\
PL & Yes \\
PT & Yes \\
RO & Yes \\
SE & Yes \\
SI & Yes \\
SK & Yes \\
UK & Yes \\
\hline &
\end{tabular}


Table E2. Non-open procedure type red flags by country, 2009-2014, EU27 plus Norway

\begin{tabular}{|c|c|c|c|c|c|c|c|c|c|}
\hline $\begin{array}{l}\text { Country } \\
\text { Code }\end{array}$ & $\begin{array}{l}\text { Accelerated } \\
\text { negotiated }\end{array}$ & $\begin{array}{l}\text { Accelerated } \\
\text { restricted }\end{array}$ & $\begin{array}{c}\text { Award } \\
\text { without } \\
\text { publication }\end{array}$ & $\begin{array}{l}\text { Competitive } \\
\text { dialogue }\end{array}$ & $\begin{array}{l}\text { Negotiated with } \\
\text { competition }\end{array}$ & $\begin{array}{l}\text { Negotiated } \\
\text { without } \\
\text { competition }\end{array}$ & Open & Restricted & Missing/error \\
\hline AT & Yes & No & Yes & Yes & No & Yes & No & No & No \\
\hline $\mathrm{BE}$ & Yes & No & Yes & No & Yes & Yes & No & No & No \\
\hline$B G$ & No & No & Yes & No & Yes & Yes & No & Yes & No \\
\hline CY & No & No & No & No & No & No & No & No & No \\
\hline $\mathrm{CZ}$ & Yes & No & Yes & Yes & No & Yes & No & No & No \\
\hline DE & Yes & Yes & Yes & No & Yes & Yes & No & No & No \\
\hline DK & No & No & Yes & Yes & Yes & Yes & No & No & No \\
\hline EE & Yes & No & Yes & Yes & No & Yes & No & No & Yes \\
\hline ES & Yes & No & Yes & No & Yes & Yes & No & No & No \\
\hline $\mathrm{FI}$ & No & Yes & Yes & No & Yes & Yes & No & No & No \\
\hline FR & Yes & Yes & No & No & Yes & Yes & No & No & No \\
\hline GR & No & No & No & No & No & No & No & No & No \\
\hline $\mathrm{HR}$ & No & No & No & No & No & No & No & Yes & No \\
\hline $\mathrm{HU}$ & Yes & Yes & No & No & Yes & Yes & No & No & No \\
\hline IE & No & No & No & Yes & Yes & No & No & No & No \\
\hline IT & Yes & No & Yes & No & No & Yes & No & Yes & No \\
\hline LT & No & No & No & No & Yes & Yes & No & No & No \\
\hline LU & No & No & No & No & No & No & No & No & No \\
\hline LV & No & No & Yes & No & Yes & Yes & No & No & No \\
\hline NL & Yes & No & Yes & No & No & Yes & No & No & No \\
\hline NO & Yes & No & Yes & No & Yes & Yes & No & No & No \\
\hline PL & Yes & No & Yes & No & Yes & Yes & No & Yes & No \\
\hline PT & No & No & Yes & No & No & Yes & No & No & Yes \\
\hline RO & Yes & Yes & No & Yes & No & Yes & No & No & No \\
\hline SE & No & No & No & No & No & Yes & No & No & No \\
\hline SI & Yes & No & Yes & Yes & No & Yes & No & No & No \\
\hline SK & Yes & Yes & No & No & Yes & Yes & No & No & No \\
\hline UK & No & Yes & Yes & No & Yes & Yes & No & No & No \\
\hline
\end{tabular}


Table E3. Advertisement period thresholds red flags by country, number of calendar days, 2009-2014, EU27 plus Norway

\begin{tabular}{|c|c|c|c|}
\hline $\begin{array}{l}\text { Country } \\
\text { code }\end{array}$ & red flag & not red flag & $\begin{array}{l}\text { is } \\
\text { "missing" } \\
\text { red flag }\end{array}$ \\
\hline AT & $0-20 ; 34-47$ & $21-33 ; 48-$ & \\
\hline $\mathrm{BE}$ & $18-34 ; 78-$ & & Yes \\
\hline$B G$ & $0-28 ; 35-$ & $29-34$ & \\
\hline CY & $0-46 ; 53-60$ & $47-52 ; 61-$ & \\
\hline$C Z$ & $0-50$ & $51-$ & \\
\hline DE & & & \\
\hline DK & 52-61 & $0-51 ; 62-$ & \\
\hline EE & $0-32 ; 50-57$ & $33-49 ; 58-$ & \\
\hline ES & $39-42 ; 52-$ & $0-38 ; 43-51$ & \\
\hline $\mathrm{FI}$ & $0-39 ; 52-$ & $40-51$ & \\
\hline FR & $0-40$ & $41-$ & \\
\hline GR & $0-54$ & $55-$ & \\
\hline $\mathrm{HR}$ & $0-40 ; 49$ & $41-48$ & \\
\hline $\mathrm{HU}$ & & & \\
\hline IE & $41-$ & $0-40$ & \\
\hline IT & $0-47$ & 48- & \\
\hline LT & $40-42 ; 48-$ & $0-39 ; 43-47$ & \\
\hline LU & $51-54 ; 86-$ & $0-50 ; 55-85$ & \\
\hline LV & $0-40 ; 51-57$ & $41-50 ; 58-$ & \\
\hline NL & $0-38 ; 48-56$ & $39-47 ; 57-$ & \\
\hline NO & $\begin{array}{c}36-42 ; 50- \\
56\end{array}$ & $\begin{array}{c}0-35 ; 43- \\
49: 57-\end{array}$ & \\
\hline PL & $0-25 ; 43-$ & $26-42$ & \\
\hline PT & $0-42$ & 43- & \\
\hline RO & $41-50$ & $0-40 ; 51-$ & \\
\hline SE & & & \\
\hline SI & $51-$ & $0-50$ & \\
\hline SK & $49-52$ & $0-48 ; 53-$ & \\
\hline UK & $0-53$ & 54- & \\
\hline
\end{tabular}


Table E4. Decision period thresholds red flags by country, number of calendar days, 2009-2014, EU27 plus Norway

\begin{tabular}{|l|ccc|}
\hline $\begin{array}{l}\text { Country } \\
\text { code }\end{array}$ & red flag & $\begin{array}{c}\text { not red } \\
\text { flag }\end{array}$ & $\begin{array}{c}\text { is "missing" } \\
\text { red flag }\end{array}$ \\
\hline AT & $0-56$ & $57-$ & Yes \\
BE & $0-22$ & $23-$ & \\
BG & $0-27 ; 120-$ & $28-119$ & \\
CY & $0-90$ & $91-$ & \\
CZ & $0-147$ & $148-$ & \\
DE & $0-36$ & $37-$ & Yes \\
DK & $0-39 ; 124-$ & $40-123$ & \\
EE & 168 & $42-$ & Yes \\
ES & $0-41$ & $41-$ & \\
FI & $0-43$ & $44-$ & \\
FR & $0-65 ; 92-127$ & $66-91 ; 128-$ & \\
GR & $0-66 ; 156-$ & $67-155$ & \\
HR & $0-170$ & $171-$ & \\
HU & $0-26$ & $27-$ & \\
IE & $0-46 ; 73-104$ & $47-72 ; 104-$ & \\
IT & $0-50 ; 87-$ & $51-86$ & \\
LT & $0-200$ & $201-$ & \\
LU & $0-32$ & $33-$ & \\
LV & $0-52$ & $53-$ & \\
NL & $0-20 ; 106-$ & $21-105$ & \\
NO & $0-34 ; 58-$ & $35-57$ & \\
PL & $0-70 ; 98-229$ & $71-97 ; 230-$ & \\
PT & $0-63$ & $64-$ & Yes \\
RO & $0-63 ; 243-$ & $64-242$ & \\
SE & $0-56$ & $57-$ & Yes \\
SI & $0-44 ; 89-$ & $45-88$ & \\
SK & $0-51 ; 77-$ & $52-76$ & \\
UK & $0-68$ & $69-$ & \\
& $0-35 ; 165-$ & $36-$ & \\
& 304 & $164 ; 305-$ & \\
& \multicolumn{3}{|c}{} \\
\end{tabular}


Table E5. Non-quantitative assessment criteria weight red flags by country, number of calendar days, 2009-2014, EU27 plus Norway

\begin{tabular}{|l|cc|}
\hline Countr & red flag & not red flag \\
y code & $0-39 ; 61-100$ & $40-60$ \\
\hline AT & $0-30 ; 71-100$ & $31-70$ \\
BE & "Lowest price" & \\
BG & & \\
CY & "Most economically advantageous & \\
CZ & tender" & \\
DE & $0-47 ; 66-100$ & $48-65$ \\
DK & $66-100$ & $0-65$ \\
EE & $11-40 ; 71-100$ & $0-10 ; 41-70$ \\
ES & "Lowest price" & \\
FI & $0-20 ; 56-100$ & $21-55$ \\
FR & $0-35$ & $36-100$ \\
GR & "Most economically advantageous \\
HR & tender" & \\
HU & "lowest price" \\
IE & $60-92$ & \\
IT & $21-40$ & $0-59 ; 93-100$ \\
LT & $0-65$ & $0-20 ; 41-100$ \\
LU & $0-40 ; 61-100$ & $66-100$ \\
LV & "Lowest price" & $41-60$ \\
NL & $61-100$ & \\
NO & $0-55$ & $0-60$ \\
PL & $0-20$ & $56-100$ \\
PT & $0-40$ & $21-100$ \\
RO & "Lowest price" & $41-100$ \\
SE & $0-49$ & \\
SI & $20-30$ & $50-100$ \\
SK & $0-15 ; 26-60$ & $0-19 ; 31-100$ \\
UK & "Lowest price" & $16-25 ; 61-100$ \\
& $0-45 ; 71-100$ & $46-70$ \\
\hline
\end{tabular}


BIBLIOGRAPHY FOR ANNEXESCharron, N., Dahlström, C., Fazekas, M., \& Lapuente, V. (2017). Careers, Connections, and Corruption Risks: Investigating the impact of bureaucratic meritocracy on public procurement processes. Journal of Politics, 79(1), 89-103.

Chong, E., Klien, M., \& Saussier, S. (2015). The Quality of Governance and the Use of Negotiated Procurement Procedures: Evidence from the European Union (EPPP DP No. 2015-3). Paris.

DG GROWTH. (2015). TED Structured Dataset (2009-2014), Tenders Electronic Daily, supplement to the Official Journal of the European Union. Brussels.

Escresa, L., \& Picci, L. (2016). Trends in Corruptions Around the World. European Journal on Criminal Policy and Research, 22(3), 543-564.

Fazekas, M., Cingolani, L., \& Tóth, B. (2016). A comprehensive review of objective corruption proxies in public procurement: risky actors, transactions, and vehicles of rent extraction (Government Transparency Institute Working Paper Series No. GTI-WP/2016:03). Budapest.

Fazekas, M., Tóth, I. J., \& King, L. P. (2016). An Objective Corruption Risk Index Using Public Procurement Data. European Journal of Criminal Policy and Research, 22(3), 369-397.

Golden, M. A., \& Picci, L. (2005). Proposal for a New Measure of Corruption, 
illustrated with Italian data. Economics \& Politics, 17(1), 37-75.

Klasnja, M. (2016). Corruption and the Incumbency Disadvantage: Theory and Evidence. Journal of Politics, 77(4), 928-942.

OECD. (2007). Integrity in Public Procurement. Good Practice from $A$ to $Z$. Paris: OECD.

Pricewaterhouse Coopers. (2013). Identifying and reducing corruption in public procurement in the EU. Brussels: PricewaterhouseCoopers and Ecorys.

Sequeira, S. (2012). Advances in Measuring Corruption in the Field. In D. Serra \& L. Wantchekon (Eds.), New Advances in Experimental Research on Corruption (pp. 145-176). Bingley, UK: Emerald Publishing.

Transparency International. (2006). Handbook for Curbing Corruption in Public Procurement. Berlin: Transparency International.

World Bank. (2009). Fraud and Corruption. Awareness Handbook. Washington DC: World Bank. 
